\title{
Ontario's law curbing the cost of generic drugs sparks changes for pharmacies and other Canadian buyers
}

$\mathrm{O}$ ntario shook up the world of generic drug pricing across the country 3 years ago when it passed Bill 102, the Transparent Drug System for Patients Act.

In turn, the executive officer of Ontario's \$4-billion-a-year drug benefit plan saw her own life disrupted.

In late April, Helen Stevenson was flanked by plainclothes Ontario Provincial Police bodyguards when she delivered a speech to IMS Health Canada. It was the day after the province announced a series of legal actions and imposed penalties totaling $\$ 33.8$ million in a crackdown on violations of the Act.

Stevenson confirms that her need for security continues because of threats made in connection with her job.

For complicated reasons, Canadian prices for generic drugs - copies of brand-name drugs which have lost patent protection - are among the highest in the world. (See Patented Medicine Prices Review Board, NonPatented Prescription Drug Prices Reporting, 2006.)

Ontario's legislation aimed to reduce the province's drug benefit plan costs by exposing, and correcting, some of the murky and hidden practices that contribute to those high prices (CMAJ 2006;175[4]:342-3).

The province banned rebates that generic manufacturers were paying to pharmacies to induce them to stock their company's version of a generic drug rebates estimated to average $40 \%$ off the invoice price. In essence, pharmacies obtained the drugs at low wholesale prices but invoiced the government at the often significantly higher prices listed in the provincial drug formulary.

At the same time, Ontario slashed the amount it will pay pharmacies for the generic forms of drugs from an average of $63 \%$ of the list price for the brandname version to $50 \%$.

As a result, the province "is spending less money and funding more drugs," Stevenson says. Savings in 2008/09 amounting to \$253 million were achieved through lower generic prices as well as some volume discount agreements with brand-name drug manufacturers, according to a ministry of health spokesperson.

The province "took a leadership role from a policy standpoint and the last couple of years has seen more change

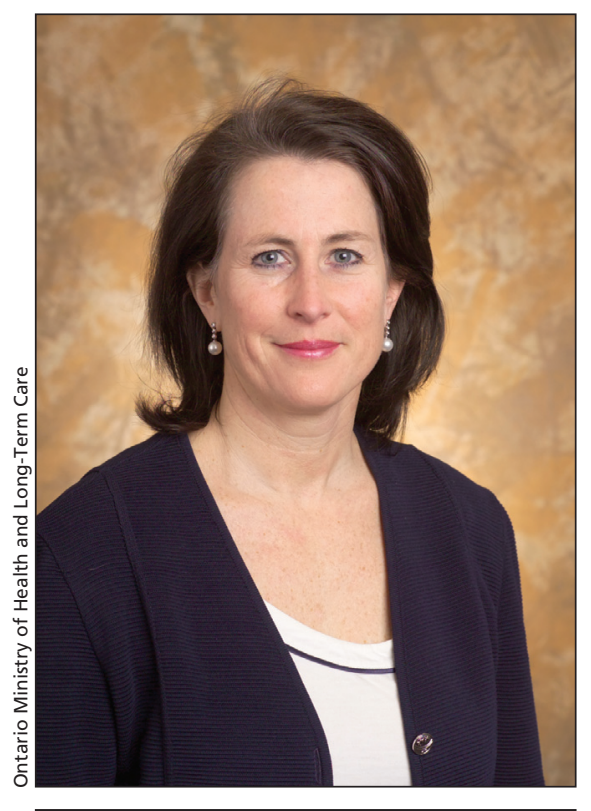

Helen Stevenson, executive officer of the Ontario drug benefit plan, required bodyguards after the provincial government passed its Transparent Drug System for Patients Act.

than the 10 previous years combined,' says pharmacist Mike Sullivan, president of Cubic Health Inc., a drug plan management company in Toronto, Ontario.

The new law "set in motion change across the country," confirms Jim Keon, president of the Canadian Generic Pharmaceutical Association.

But the law has proved controversial. It has "created an awareness in the marketplace of what is really going on, and that is probably having a good impact," says Barbara Martinez, senior health and benefits associate with Mercer Human Resources Consulting in Toronto.

On the other hand, the Ontario drug plan "basically lowered their own price and as a response pharmacies are charging private plans much more in Ontario," she says. As well, many other provinces have not been able to match Ontario's prices.

When Ontario changed its rules, it upset the apple cart for other payers because its drug formulary had previously been used "as the price point across the country," says Mark Ronayne, a coauthor of the Canadian Generic Drug Sector Study, a 2007 report from the federal Competition Bureau.

"Other provinces realized they couldn't depend on the old system and prices split apart all over the country," adds Aidan Hollis, economics professor at the University of Calgary and author of the 2009 report, Generic Drug Pricing and Procurement: A Policy for Alberta.

The murky practices that Ontario set out to expose were also scrutinized by the Competition Bureau's 2007 report.

It noted that government drug plans, private plans and cash-paying Canadians don't benefit from the competition that exists among generic drug manufacturers who vie to have pharmacies stock their generic versions of brandname drugs by offering rebates or other incentives. Pharmacies receive the rebates but don't pass on the savings to private or public plan purchasers, the federal agency report stated.

In a 2008 report he coauthored, Paul Grootendorst, an associate professor of pharmacy at the University of Toronto, estimated the rebate income in 2006 for the "average pharmacy" (one that fills 30000 generic prescriptions a year) to be about $\$ 240000$.

Although the province banned rebates, it allows generic manufacturers to pay pharmacies up to $20 \%$ above the drug price for "professional allowances," which have to be reported by both par- 
ties. (Any payment above the $20 \%$, with respect to the provincial drug plan, is deemed a rebate under the law.)

The professional allowances, capped at $20 \%$ for the provincial drug plan (but not capped for private payers), are to be spent on patient-related services and are subject to audit by the province.

For 2008, manufacturers reported paying a total of $\$ 680$ million in professional allowances to pharmacies. (Interestingly, the Ontario health ministry estimated the rebate payouts made before 2006 to be a similar annual amount: between $\$ 600$ million and $\$ 800$ million.)

This capping and redirection of rebate payments is part of a growing trend to reimburse pharmacists more explicitly for clinical and cognitive services, instead of having their professional services tied to the price of drugs. (Ontario also introduced the MedsCheck program, under which it reimburses pharmacists to provide annual consultations of up to 30 minutes for individuals taking 3 or more prescription drugs a day.)

"I don't think the system now serves the pharmacy profession's need to see their skills recognized," Grootendorst says. The model in which pharmacists' pay is tied to dispensing medicine "is going to be under increasing pressure as employer groups and others clamour for lower prices."

Nadine Saby, president and chief executive officer of the Canadian Association of Chain Drug Stores, warned that efforts to reduce generic drug prices could cause pharmacies to "suffer unintended collateral damage." Chains and franchises now comprise about $60 \%$ of the more than 8000 retail pharmacies in Canada.

Pharmacy sustainability and the services "are linked in part to the price of generic drugs," she said in a speech to the Economic Club of Toronto in 2008. "As government drug plans seek to reduce generic drug prices, the funding gap will worsen unless appropriate changes are made to the reimbursement model for pharmacies."

In its draft Blueprint for Pharmacy, the Canadian Pharmacists Association notes that government caps on compensation for dispensing fees have contributed to a reliance on payments from drug manufacturers. Executive Director

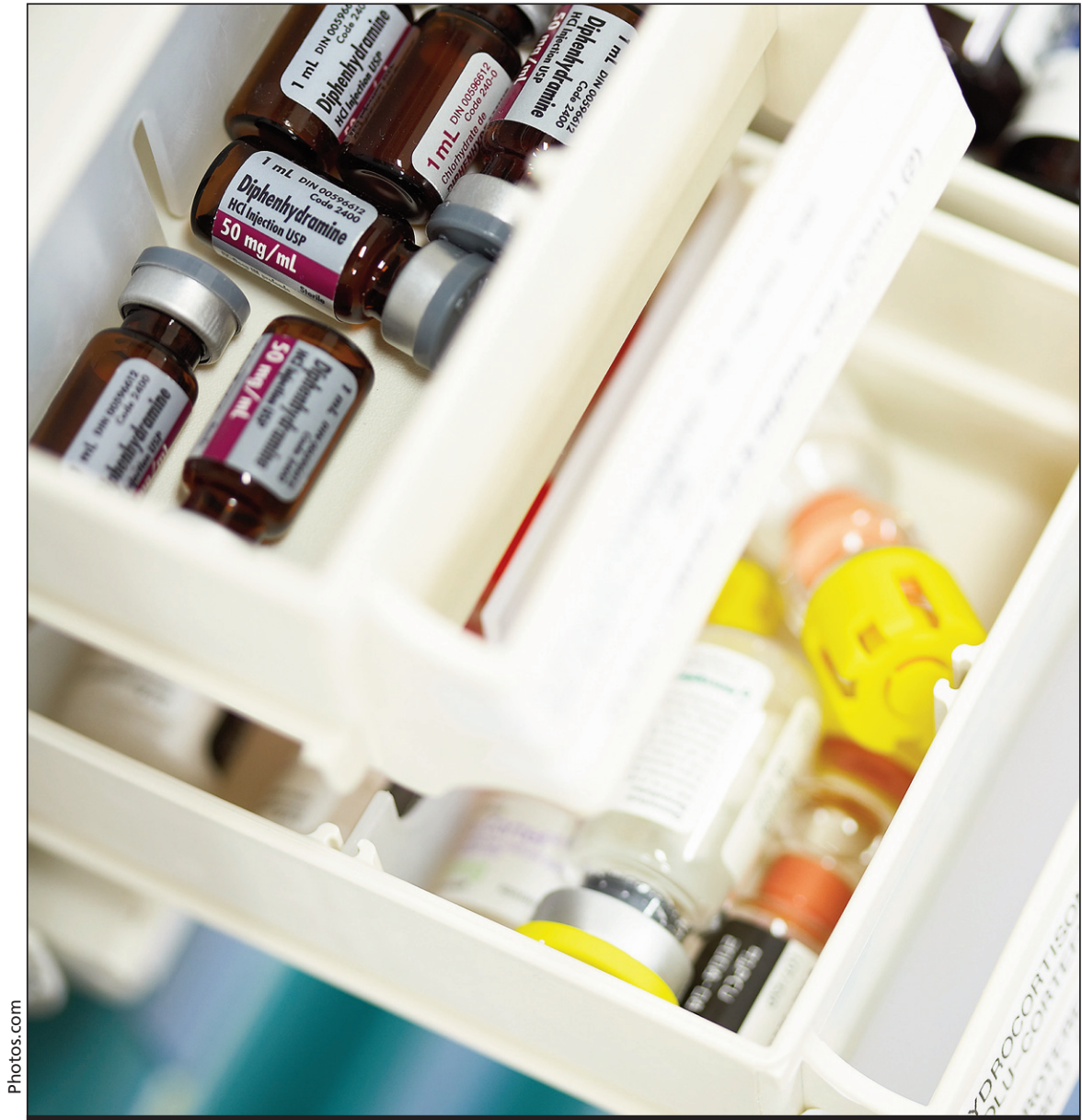

The Competition Bureau says Canadians can save $\$ 800$ million annually in drug costs.

Jess Poston cites 3 provincial studies that identify a $\$ 4$ or $\$ 5$ per-prescription gap between government reiumbursement levels for dispensing fees and the actual cost to pharmacies. "Relying upon revenues from other sources ... to subsidize a pharmacy's dispensing services is not a sustainable business model," the draft blueprint states.

A 2008 report from the Competition Bureau, Benefiting from Generic Drug Competition in Canada: The Way Forward, states that, as well as helping to finance pharmacy services to patients, the rebates may have other effects, such as increasing pharmacy profits and advertising, financing extended hours of operation, and facilitating investment in a store's appearance to attract more patients.

Meanwhile, spending on generic drugs is increasing across the country. Between 2006 and 2007, generic drug expenditures increased more than $20 \%$ to $\$ 4.1$ billion and that amount is expected to increase as several highly prescribed drugs are scheduled to come off patent in the next few years, the 2008 report states. Generics currently fill $52 \%$ of prescriptions written in Canada, but account for only $24 \%$ of the total amount spent on prescription drugs, says Keon.

Canadians stand to save $\$ 800$ million a year in drug costs if changes are made to the way drugs are paid for, states the 2008 Competition Bureau report, which recommends the separation of reimbursement for professional services from drug costs.

To benefit from generic drug competition, public plans should "introduce measures for reimbursing pharmacies for the true cost of their drugs [and] reimburse pharmacy services such as dispensing and patient counselling separately from drug costs," the report stated.

Some pharmacists protested when the Ontario legislation was introduced 3 years ago. While average pharmacy profits in Canada "remain strong" at 
\$207 600 for 2008, Ontario pharmacies saw their average profits fall below the national average for the first time in 2008, according to Community Pharmacy 2008, a report prepared by industry representatives.

Still, when Ontario received the reports, required by law, from manufacturers and pharmacies about the amount of professional allowances paid and received, it "found huge discrepancies," Stevenson says. "We did an audit to understand the discrepancies and found even more issues."
The province's 8 enforcement staff, aided by auditors from the provincial finance ministry, uncovered a drug recycling scheme. Some pharmacies were purchasing "a greater quantity of generic drugs than they require," collecting the professional allowance and then returning a portion to wholesalers that resold that product, according to the Ministry of Health and Long-Term Care.

In late April and early May, the ministry issued rebate penalty orders, laid provincial offence charges for providing false or misleading information, put several pharmacies on notice that their agreements could be terminated, and filed complaints with the Ontario College of Pharmacists and Health Canada.

More enforcement actions may be forthcoming, Stevenson says. - Ann Silversides, $C M A J$

DOI:10.1503/cmaj.091155

Provincial drug plan changes: Coming soon, how other Canadian provinces are addressing high drug costs.

\section{Private payers "wake up" to drug price gap}

Ontario's success in ratcheting down the amount it pays for generic drugs has not been matched by private drug benefit plans and employers are "starting to wake up," says Barbara Martinez, senior health and benefits associate with Mercer Human Resources Consulting in Toronto.

"There is this terrible disparity in prices ... but they can't react quickly. Changing benefit programs is a slow process."

Businesses are paying attention because they are facing tough economic times and "can't afford not to address" the issue of drug pricing, says Mark Ronayne, senior competition law officer with the Competition Bureau Canada and coauthor of 2 reports on generic drug competition.

Private drug plans, which account for $52 \%$ of generic drug expenditures in Canada, could save $\$ 600$ million a year if they could buy generics drugs at competitive prices, according to the bureau's 2008 report Benefiting from Generic Drug Competition.

Before Ontario introduced the Transparent Drug System for Patients Act in 2006, the province's prescription drug formulary set the standard for pricing, for private and most public payers, across the country.

In Ontario, the provincial public plan and the private plans traditionally paid the same price for the ingredient and the mark up on drugs, with the key difference in cost being the amount of the dispensing fee, Martinez explains.

But today the cost spread is much wider. For example, a generic version of a brand-name drug priced at $\$ 100$ would now cost the province $\$ 61$ and private plans $\$ 87$, compared to prices of $\$ 75.41$ and $\$ 79.30$ before the 2006 Act, she says. (Those amounts include markups and dispensing fees charged by pharmacies.)

Helen Stevenson, executive officer of the Ontario drug plan, says she "would shy away from any suggestion that we have shifted costs as a result of these changes."

Instead, the assistant deputy minister of health says the province "opened the doors as much as we possibly could for the private market to follow our changes."

In fact, the majority of private drug benefit plans are administered for companies by outside firms - mainly insurance companies - that are often paid a percentage of plan costs. As a result, there is "absolutely no incentive" for them to rein in prices, says Mike Sullivan, president of Cubic Health Inc., a Toronto-based drug plan management company. Increasingly, employers are moving to a pertransaction fee, he said.

Among private payers, only about $17 \%$ in Canada have managed plans, where a cost-benefit analysis of drug coverage is undertaken, according to data from ESI Canada, a health claims management company.

Ontario's legislation "has had an impact on the economics of pharmacy so, like any business, they are looking at ways to make up what is perceived to be a revenue shortfall," says Sullivan.

For example, he says his firm has noticed a much wider range in ingredient costs for the same drug submitted by different pharmacies for reimbursement. Among Ontario pharmacies in 2007, the difference in ingredient costs between high and low prices for chronic medications ranged from $37 \%$ to $95 \%$. "There has always been variation, but never to this degree," he says.

Martinez says that this year, employers have started to come to her asking about negotiating with mail-order pharmacies to try to get down to the lower prices paid by the province.

Greater use of mail-order pharmacies was one of the strategies for businesses to obtain savings described by the Competition Bureau's 2008 report. Others include developing preferred pharmacy networks and providing patients with incentives to seek lower prices.

Meanwhile, it is the cash-paying customer without a drug plan who typically pays the highest price for prescription drugs. Sullivan says many pharmacy computers are set up so that if a regular pharmacy client loses their employerpaid benefits, and that information is entered on the screen, "a completely different" higher price for the prescription automatically pops up. 